\title{
Observatório
}

DOI: http://dx.doi.org/10.20873/uft.2447-4266.2015v1n3p181

\section{Memória e filmes domésticos em Super 8: a família Assis em Juiz de Fora (MG)}

Memory and Super 8 home movies: the Assis family at Juiz de Fora (MG)

Memoria y cine doméstico en Super 8: la familia Assis en Juiz de Fora (MG)

\section{Christina Ferraz Musse ${ }^{1}$ Ana Clara Campos dos Santos ${ }^{2,3}$}

\section{RESUMO}

Neste trabalho abordamos a memória como objeto de estudo, a película cinematográfica Super 8 e os filmes domésticos. No embasamento teórico, utilizamos autores como Andreas Huyssen e Pierre Nora (memória), Roger Odin e Lila Foster (filmes domésticos). Nosso objetivo é apresentar os filmes em Super 8 feitos pelo fotógrafo Márcio Assis na década de 1970, a fim de verificar as relações entre sua narrativa oral atual por meio da gravação em áudio de seus comentários do filme, em comparação a sua narrativa visual sobre a própria família na década de 1970. Também fazemos um estudo de como os familiares de Márcio Assis assistem a esses filmes, cerca de quarenta anos depois, por meio da coleta de depoimentos nas redes sociais e entrevistas.

PALAVRAS-CHAVE: Audiovisual; memória; Super 8; filmes domésticos.

1 Vice-coordenadora do Programa de Pós-Graduação em Comunicação da Universidade Federal de Juiz de Fora (PPGCOM/UFJF). Líder do grupo de pesquisa Comunicação, Cidade e Memória. Mestre e Doutora em Comunicação pela UFRJ (2006). E-mail: musse@terra.com.br.

2 Mestranda em Comunicação na Universidade Federal de Juiz de Fora (UFJF). Graduada em Jornalismo (UFJF) e integrante do grupo de pesquisa Comunicação, Cidade e Memória. E-mail: anaclaracs91@gmail.com.

${ }^{3}$ Endereço de contato das autoras (por correio): Universidade Federal de Juiz de Fora. Programa de Pós-Graduação em Comunicação. Campus Universitário de Martelos. Rua José Lourenço Kelmer, s/n, Bairro Martelos, Juiz de Fora - MG, Brasil. CEP 36036-330. 


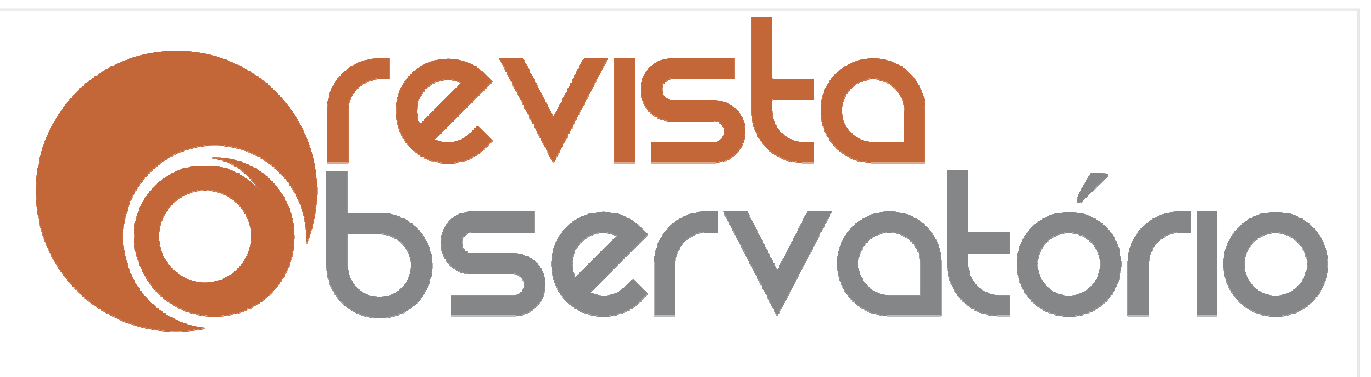

DOI: http://dx.doi.org/10.20873/uft.2447-4266.2015v1n3p181

\begin{abstract}
In this paper we address the memory as an object of study, the motion picture film and Super 8 home movies. On theoretical basis, we use authors like Andreas Huyssen and Pierre Nora (memory), Roger Odin and Lila Foster (home movies). Our goal is to present Super 8 films made by the photographer Marcio Assis in the 1970s in order to verify the relationship between his current oral narrative through the audio recording of his comments the film, compared to its visual narrative about his own family in the 1970s. We also do a study as family Marcio Assis watch these movies, some forty years later, by collecting testimonials on social networks and interviews.
\end{abstract}

KEYWORDS: Audiovisual; memory; Super 8; home movies.

\title{
RESUMEN
}

En este artículo, abordamos la memoria como un objeto de estudio, la película cinematográfica Súper 8 y el cine doméstico. En la base teórica, utilizamos autores como Andreas Huyssen y Pierre Nora (memoria), Roger Odin y Lila Foster (cine doméstico). Nuestro objetivo es presentar las películas en Súper 8 realizadas por el fotógrafo Marcio Assis en la década de 1970 con el fin de verificar la relación entre la narrativa oral actual mediante el registro de información de audio de la película en comparación con su narrativa visual acerca de la propia familia, en la década de 1970. También hacemos un estudio de cómo la familia de Marcio Assis asiste a estas películas, unos cuarenta años más tarde, mediante la recopilación de testimonios en las redes sociales y entrevistas.

PALABRAS CLAVE: Audiovisual; memoria; Súper 8; cine doméstico.

Recebido em: 03.11.2015. Aprovado em: 10.12.2015. Publicado em: 26.12.2015. 


\section{Observatório}

DOI: http://dx.doi.org/10.20873/uft.2447-4266.2015v1n3p181

\section{Introdução}

Nos dias de hoje, a memória tem sido cada vez mais valorizada, seja na preservação da memória social, por razões políticas e de respeito aos direitos humanos, seja na criação de acervos com documentos que registrem mudanças socieoconômicas, ambientais, culturais e comportamentais em determinadas áreas de uma cidade.

O que também nos chama a atenção é que exista, atualmente, a preocupação em preservar arquivos audiovisuais em formatos digitais, para que estes não se tornem obsoletos e não sejam danificados por problemas de armazenamento e na projeção. O Home Movie Day, criado em 2002, é um evento que incentiva e realiza a digitalização de acervos pessoais em bitolas de $9.5 \mathrm{~mm}, 8 \mathrm{~mm}$, Super 8 e $16 \mathrm{~mm}$, e a posterior exibição dos filmes ao público interessado, além de oferecer oficinas e debates. O evento acontece em diversos países do mundo, mas não foram encontradas informações claras sobre onde esta ideia teve início.

A busca pela recuperação ou ressignificação de momentos vividos e o saudosismo que existe até por momentos que nunca vivemos são questões que levam os estudiosos a criar teorias sobre esse fenômeno que vem acontecendo. Por que têm ocorrido tantos projetos com iniciativas públicas e/ou privadas de tentar recuperar as memórias de décadas atrás? O pesquisador Andreas Huyssen (2004) afirma que, em uma sociedade com excesso de informações, é o medo do esquecimento que nos move e nos faz transformar tudo em memórias - inclusive na indústria do entretenimento, como em filmes que relembrem fatos ou histórias de vida, ou até mesmo nas modas vintage e retrô há bastante tempo, desde a década de 1970, na Europa e nos Estados Unidos.

Hoje, com maior acesso à internet de banda larga ${ }^{4}$, bluetooth ${ }^{5}$ e a

\footnotetext{
${ }^{4}$ Banda larga é a conexão da internet em alta velocidade, que permite ao usuário maior rapidez na navegação e para baixar e subir arquivos, como fotos, músicas e vídeos.

${ }^{5}$ Bluetooth é a tecnologia de comunicação sem fio de que permite transmissão de dados e arquivos de maneira rápida através de celulares, notebooks, câmeras digitais, entre outros aparelhos 


\section{Observotório}

DOI: $\underline{\text { http://dx.doi.org/10.20873/uft.2447-4266.2015v1n3p181 }}$

popularização de câmeras digitais, redes sociais e sites de compartilhamento de vídeos, a informação corre muito mais rápido. Só não se informa quem não quer ou é impedido de ter acesso. Paradoxalmente, é a sobrecarga de informações que, segundo Huyssen, também nos empurra para o esquecimento. Ele aponta o seguinte motivo: "quanto mais rápido somos empurrados para o futuro global que não nos inspira confiança, mais forte é o nosso desejo de ir mais devagar e mais nos voltamos para a memória em busca de conforto" (HUYSSEN, 2004, p.32). O autor afirma que, por essa razão, somos assolados pelo medo do esquecimento e defende que a maneira que encontramos de acabar com esse medo é produzindo cada vez mais arquivos que preservem nossas memórias, para nos protegermos contra 0 encurtamento de tempo e espaço.

Na definição do historiador Pierre Nora (1993), a memória é algo que surge em um grupo vivo no qual está inserida, permanecendo em constante evolução; já a história é uma reconstrução do passado, daquilo que não existe mais (NORA, 1993, p.09). Nora é conhecido por seu conceito de "lugar de memória", que são locais materiais, simbólicos e funcionais, onde mantemos os arquivos que nos ajudam a guardar os instantes que se passaram e são dignos ou necessários de serem recordados. Segundo o autor, quanto menos a memória é vivida e relembrada no interior de cada pessoa, mais ela precisa de suportes através dos quais possa sobreviver e ser perpetuada, preservando o passado e o presente. Trata-se de uma obsessão por produzir e guardar esses arquivos. Torna-se, então, quase uma obrigação produzir arquivos de memória, para que a história não seja perdida ou destruída.

\section{O Super 8 e suas particularidades técnicas}

A película Super 8 foi amplamente utilizada no Brasil na década de 1970 entre 


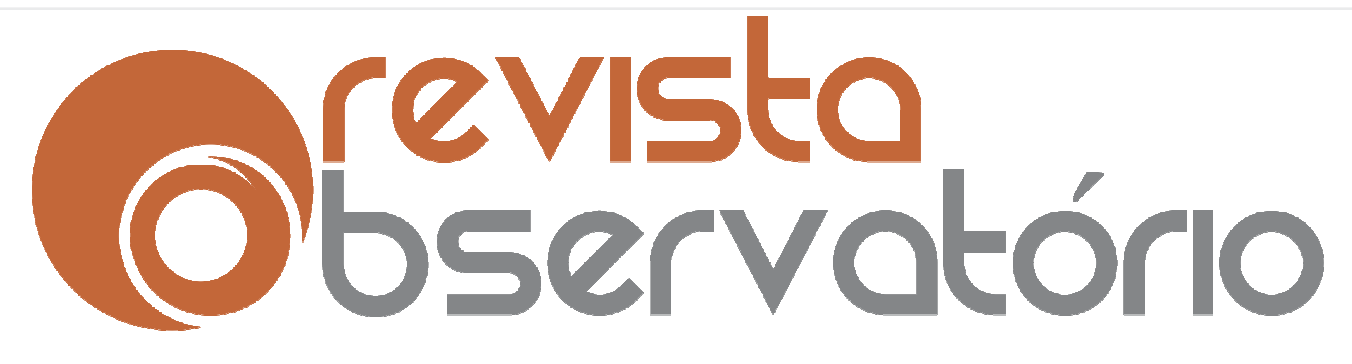

DOI: http://dx.doi.org/10.20873/uft.2447-4266.2015v1n3p181

cineastas amadores, para eventos sociais e registros familiares. Para fazer filmes em Super 8 havia algumas características peculiares que a diferenciavam de outras películas. A câmera era portátil e simples de usar, facilitando principalmente o acesso da classe média à bitola, já que ainda tinha custos muito altos para ser acessível as camadas mais populares.

O Super 8 é uma película com largura de 8 milímetros, porém, diferente da primeira película de $8 \mathrm{~mm}$ criada: o Super 8 tinha maior área de exposição do que o $8 \mathrm{~mm}$, o que tornava a imagem de melhor qualidade. Na câmera da tradicional $8 \mathrm{~mm}$, o filme vinha em um carretel, era colocado na câmera até se usar a metade (quatro minutos, em um total de oito), então, abria-se a câmera, virava-se o filme e usava-se os outros quatro minutos. O Super 8 era um aperfeiçoamento do $8 \mathrm{~mm}$ e mais simples de ser usado: a bitola vinha em um cartucho de pressão que era posto na câmera e não precisava ser virado.

Por se tratar de um filme reversível, ou seja, o original é positivo e não um negativo, os custos para a revelação eram mais baratos e a projeção, mais viável. 0 filme positivo já era pronto para projeção. Mas, apesar da praticidade e da economia proporcionadas pelo Super 8 , filmar nessa película tinha alguns problemas. 0 filme positivo fazia com que o processo de cópias fosse muito difícil, então era raro e muito caro se fazer cópias. Isso tornava a película original única e passível de perda, não podendo ser recuperada.

Antes da película Super 8, outras câmeras foram lançadas no mercado para produção de filmes caseiros, mas a película foi o salto para inclusão da classe média e massificação de produtos desse tipo. Dargy (1979) afirmava que a película era, sem dúvida, a mais aperfeiçoada e completa à disposição do cineasta amador. $\mathrm{O}$ autor tratava a película como objeto de interesse de pequenos cineastas e dava dicas dos primeiros passos na produção desses filmes. Apesar de Dargy considerar a película um meio de se fazer cinema, ele considerava que a prática de filmar em Super 8 deveria se limitar ao campo doméstico, familiar. $O$ autor também divide o cinema 


\section{Observotório}

DOI: http://dx.doi.org/10.20873/uft.2447-4266.2015v1n3p181

amador em duas categorias: 1) filmes elaborados, mesmo que de maneira simples (documentário, filme com roteiro, desenho animado); e 2) filmes sem roteiro ou espontâneos (filme familiar, filme de viagem, reportagem). Dessa forma, vemos que uma das principais funções das câmeras de bitola Super 8 era a de realizar registros caseiros (DARGY, 1979).

O que pretendemos abordar aqui é o caráter de afeição ao Super 8, a função doméstica da película e como ela cria a sensação de saudosismo como suporte de memórias familiares. Os filmes, geralmente mostrando momentos felizes e de tranquilidade, eram mandados para a revelação e, posteriormente, exibidos em sessões de cinema particulares, estrelados pelos próprios personagens que assistiam a eles. É esse aspecto informal, de captar o presente espontâneo e não-ficcional, de documentar viagens, eventos e cerimônias, que nos interessa estudar na película Super 8.

\section{Filmes domésticos: características e definições}

Atualmente, tem crescido o número de produções sobre os filmes familiares e sua importância para a memória social. Para o pesquisador Roger Odin (2010, p.3940), o cinema doméstico é feito por um integrante da família, com imagens de pessoas e acontecimentos que tenham alguma relação com essa família e usado e assistido preferencialmente por membros da mesma família. Mesmo que a maioria das cenas mostre a interação dos parentes, o conteúdo dos filmes não é essencialmente este, mas tudo o que for considerado importante para ser exibido e guardado, segundo o cineasta. Para Carlos Caruso (2012), a definição de filme doméstico abrange também os filmes feitos à parte do núcleo familiar, como aqueles realizados em companhia de amigos próximos "para preservar essas recordações e momentos significativos vividos em conjunto" (CARUSO, 2012, p.21).

Ao pesquisar a literatura sobre filmes domésticos, podemos definir o que 


\section{Observotório}

DOI: http://dx.doi.org/10.20873/uft.2447-4266.2015v1n3p181

consideramos as principais características do gênero:

1) Felicidade: A maioria dos filmes domésticos mostram momentos felizes, de tranquilidade e paz, longe das questões preocupantes ou que causam tristeza, como os dilemas existenciais, o trabalho, a morte, as brigas entre integrantes da família. Porém, de acordo com o cineasta Alan Berliner (2004, apud ÁLVAREZ, 2010), esses filmes são falsas representações ideais de uma família perfeita. Dessa forma, os filmes domésticos mostram apenas um lado da vida das pessoas filmadas. Elas se tornam personagens fictícios, pois naquelas cenas não são externadas as relações mais profundas do ser humano.

2) Narrativa não-linear: Os filmes caseiros geralmente registram acontecimentos sem uma narrativa completa, ou seja, não são compostas de início, meio e fim notadamente definidos. O cineasta leva a câmera a uma festa, a um piquenique, a um jantar da família, a uma viagem entre amigos, mas não pretende filmar os eventos do início ao fim. De acordo com Roger Odin (2010, p.41-42), os filmes domésticos não têm uma narrativa com início e fim especificados, são inacabados, como se fossem partes de um texto, fragmentos de ações. Além disso, os registros não possuem uma marcação temporal, a não ser em alguns vídeos nos quais são registradas data e hora, mas, mesmo assim, o tempo é indicado, mas sem uma significância determinada. Na definição de Odin, esses fatores são chamados de ausência de encerramento, dispersão narrativa e temporalidade indeterminada. Se não se faz uso de outros recursos (textuais ou de narração oral) durante a exibição, talvez não fiquem claros os motivos pelos quais aquelas cenas foram registradas, nem a importância que aquele documento possui para a família.

3) Ausência de técnica: Imagens fora de foco, com enquadramento ruim, tremidas (sem uma base onde colocar a câmera), muito escuras ou claras demais (sem a iluminação correta), um dedo intrometido na lente da câmera, som de palavras incompreensíveis, barulho de vento (ausência de microfone unidirecional). Essas são algumas das falhas características dos filmes domésticos. Obviamente, 


\section{Observotório}

DOI: http://dx.doi.org/10.20873/uft.2447-4266.2015v1n3p181

esses "erros" são cometidos por quem não costuma ter contato com a câmera filmadora e conhecimento da técnica, ou por quem tem algum conhecimento, mas não possui os equipamentos necessários naquele momento - fato que torna o filme ainda mais espontâneo. De acordo com Odin, "o cinema doméstico, longe de funcionar apesar dos fatores que o tornam 'malfeito', funciona corretamente graças a esse conjunto de fatores" ${ }^{\prime \prime}$ (ODIN, 2010, p. 52, tradução nossa). Ou seja, o correto é estar errado, quando se trata de filmes domésticos.

4) Cineasta participante: Diferentemente do cineasta amador, o cineasta de família quer registrar os momentos da família, porém, sem preocupação com a técnica ou com o resultado final do trabalho. Mesmo assim, nos filmes domésticos a câmera não é ignorada, pelo contrário: de acordo com as pesquisadoras Consuelo Lins e Thais Blank (2012), existe uma interação peculiar entre o cineasta, na figura da câmera, e as pessoas que estão sendo filmadas. Um membro da família pode ser um cineasta doméstico ou amador. Segundo as autoras, ambos registram a história cotidiana, mas o cineasta de família acompanha os passos dos filhos, registrando os acontecimentos que consideram mais marcantes, enquanto o cineasta amador se preocupa em fazer cinema preocupado com a técnica, como os cineastas de carreira, não se contendo à simples filmagem de seus familiares.

As autoras Lila Foster (2010) e Marilia Leal (2013) também falam sobre os filmes contratados para registrar eventos importantes para a família (em celebrações como casamentos, aniversários, batizados, formaturas). Foster ressalta que essas imagens produzidas garantem um status desejado pela família. Leal aponta que esses filmes, feitos por profissionais, levam a um distanciamento entre quem filma e os personagens, que ignoram a presença da câmera, dando ao arquivo um caráter mais formal.

5) Função de ressignificação: O que importa é a exibição dos filmes; assisti-los

\footnotetext{
${ }^{6}$ Tradução livre da autora para o original: "el cine doméstico, lejos de funcionar a pesar de las figuras que lo muestra como 'mal hecho', funciona correctamente gracias a ese conjunto de figuras".
} 


\section{Obsisto
Obrvónio}

DOI: http://dx.doi.org/10.20873/uft.2447-4266.2015v1n3p181

depois de prontos, mesmo que as imagens por si só não façam sentido, pois, na projeção, elas são ressignificadas pelos membros da família, de acordo com ODIN (2010). Dessa forma, conclui-se que, quanto menos elaborado for o filme, melhor é a sua função de ressignificação no âmbito familiar. O espectador de um filme doméstico não é apenas aquele que assiste ao filme, mas é também um personagem e participante ativo nas sessões. De acordo com Lila Foster (2010), o momento mais importante na realização desse gênero é o de projeção dos filmes, a presença daqueles personagens bem conhecidos de todos os que estão diante da tela. Esses momentos de projeção e a proximidade são fortalecidos pelo aspecto estético dos filmes domésticos, quase sempre improvisados. Dessa forma, "o filme de família serve para re-apresentar esses momentos a essas pessoas" (FOSTER, 2010, p.30).

6) Documento histórico: De acordo com Caruso (2012), os filmes domésticos feitos principalmente entre membros de uma família registram o cotidiano, mostrando quais as tecnologias usadas em determinada época, como se deu a urbanização de tal cidade, quais eram as roupas e hábitos frequentes em um grupo social. Esses filmes são documentos legítimos que contribuem para a história, "especialmente de épocas nas quais a produção oficial de determinados países (como o Brasil) sofre um controle por órgãos oficiais" (Home Movie Day, 2013). Assim, esses arquivos se tornam relíquias, documentos exclusivos de determinada época, que nos levam a uma nova reflexão acerca do que não podemos ver em fotos antigas ou livros de história. Os filmes domésticos podem ser ressignificados nos documentários atuais, por meio de um processo de reciclagem, uma nova utilização do material bruto.

\section{O filme doméstico e o registro da memória: a família Assis}

Neste trabalho vamos estudar uma família de Juiz de Fora, que existe desde que a cidade foi emancipada: a família Assis. Escolhemos esta família, pois há 


\section{Obvervotório}

DOI: http://dx.doi.org/10.20873/uft.2447-4266.2015v1n3p181

registros de que, desde a década de 1940, alguns membros da família já demonstravam interesse em cinema. Seja com a exibição de filmes para a comunidade no Cinema da Floresta ${ }^{7}$, seja na produção de filmes na Produtora de Cinema Regina, seja no interesse em produzir filmes no ambiente doméstico.

Vamos descrever e analisar a produção doméstica de Márcio Alcântara de Assis, que trabalha como fotógrafo profissional e realizou produções com a película Super 8 na década de 1970. Além disso, iremos registrar e analisar a recepção de Márcio Assis e da família, cerca de 40 anos depois de os filmes terem sido feitos, para saber como essas narrativas visuais afetam as relações que os membros da família têm uns com os outros. Atualmente, Márcio Assis trabalha para a Secretaria de Cultura do Rio de Janeiro fotografando acervos de museus.

Os filmes em Super 8 foram digitalizados por ocasião desta pesquisa com ajuda de funcionários da Funalfa ${ }^{8}$ e do Museu Ferroviário de Juiz de Fora e continham faixa sonora, mas o projetor utilizado não reproduzia som. Por questões econômicas, não foi realizada a telecinagem ${ }^{9}$ das películas. O processo de digitalização foi feito de modo informal.

A revisitação de Márcio Assis a filmes feitos quase 40 anos atrás rememora os hábitos e brincadeiras feitos entre os irmãos, filhos e sobrinhos na década de 1970: a caça aos ovos de Páscoa, o Rio de Janeiro como destino de viagem da família, vários cachorros como animais de estimação. Mas, como toda família, esta também possuía suas particularidades: O "armário da fantasia", no qual ficavam guardadas as fantasias de carnaval, e a "Chuleteca" faziam a alegria das crianças: "[Chuleteca] era uma sala com toca-discos, a molecada entrava, tirava o sapato... Na época tinha discoteca, essa aí era a Chuleteca" (ASSIS, Márcio, 2014). Além disso, a casa da família, em uma área

\footnotetext{
${ }^{7}$ Floresta é um bairro situado na zona sudeste do município brasileiro de Juiz de Fora. Para saber mais detalhes sobre a história do Cinema da Floresta, confira os artigos produzidos por Raruza Gonçalves no blog www.pesquisafacomufjf.wordpress.com

${ }^{8}$ Fundação Cultural Alfredo Ferreira Lage: órgão de administração indireta, vinculado à Prefeitura de Juiz de Fora.

9 Processo que converte a película de cinema em vídeo, podendo gravar as imagens em diversos suportes de vídeo, analógicos ou digitais.
} 


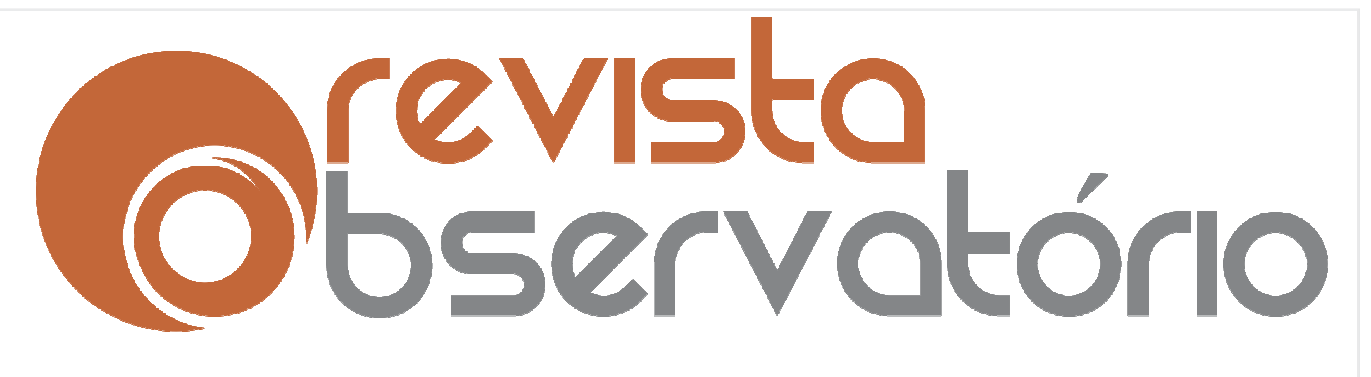

DOI: http://dx.doi.org/10.20873/uft.2447-4266.2015v1n3p181

rural, privilegiava os encontros ao ar livre, em que as crianças podiam fazer seus shows de cantoria e os donos da casa podiam criar diversos animais, como macacos e tucanos.

Para a coleta do depoimento de Márcio Assis, não foi preciso fazer muitas perguntas como em uma entrevista de história oral, para trazer à tona fatos, narrações e uma diversidade de lembranças. Os comentários feitos por ele enquanto assistíamos aos filmes não rememoravam apenas aqueles momentos filmados, mas acontecimentos habituais entre a família. Algumas das cenas foram situadas no tempo apenas por haver indicação escrita nas caixas onde estavam guardados os filmes. Em alguns momentos, os filmes trouxeram até mesmo outras lembranças não relacionadas diretamente às imagens.

Márcio Assis ficou muito satisfeito em rever seus filmes e, ao mesmo tempo em que assistia a eles, já pensava em quem mais também gostaria de vê-los. Ele comentou sobre um grupo que criou no Facebook, chamado "Primaiada", no qual os familiares podem manter contato. Logo no início do depoimento, quando colocamos os vídeos para rodar no computador, Márcio Assis comentou que colocaria os filmes para a "primaiada" assistir. Esse comentário demonstra que aquelas imagens seriam do interesse de todos aqueles do grupo familiar, algo de que Márcio sentiria orgulho em divulgar e que poderia levar aos parentes o mesmo sentimento de alegria e divertimento que sentiu, reforçando laços de união entre eles; além disso, vários integrantes do "Primaiada" participam das cenas registradas e poderiam rever a si mesmos na tela. Alguns filmes serão brevemente analisados a seguir: 


\section{Obsevisto}

ISSN n² 2447-4266

Vol. 1, n³, dezembro. 2015

DOI: http://dx.doi.org/10.20873/uft.2447-4266.2015v1n3p181

1) Páscoa e Dia das Mães (1974)

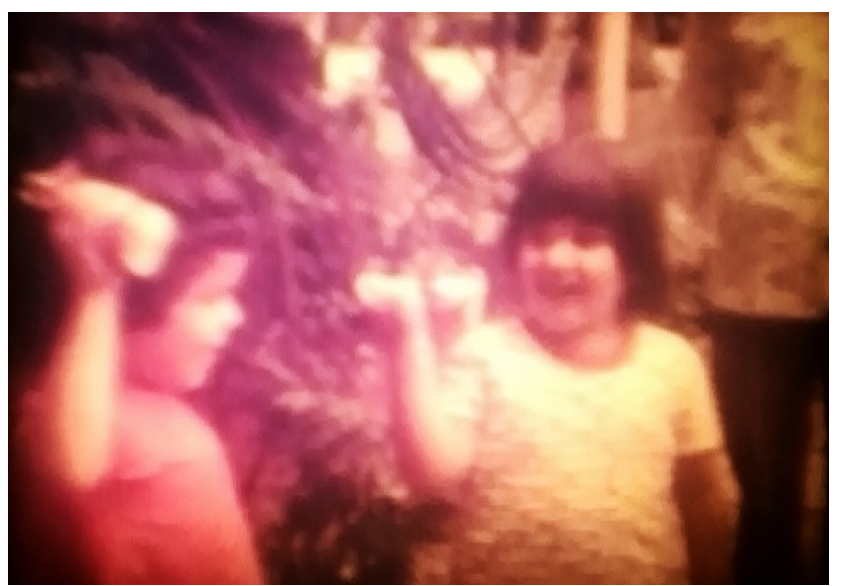

Figura 01: Crianças exibindo os chocolates que encontraram na caça aos ovos de Páscoa. Ano: 1974.

\section{Comentários no grupo "Primaiada"}

- Flavia De Assis Lustosa: "Emocionadíssima estou! Que delícia assistir isso! Ver meu pai me carregando no colo, minhas avós lindas, as brincadeiras de criança com meus primos e irmãs... Bom trabalho e boa sorte para você!"

- Regina de Assis: "Uma preciosidade a recuperação destas imagens! Bravos, Ana Clara Campos e Márcio, por guardarem e recuperarem esta linda história! Tão bom rever todas estas pessoas tão queridas!"

- Carlinha de Assis: "Que MÁXIMO! EMOCIONANTE!!! Parabéns, Ana Clara! Muito feliz em ver este vídeo! Saudades! Quero mais!"

- Mônica de Assis Delmonte: "Como não se emocionar... Momentos muito felizes!!! Amei!!! Parabéns, Ana Clara!!! Também quero mais! Bjs."

- Bianca Marques: "Coisa mais linda, né? Fiquei muito emocionada quando vi... Vó escondendo nossos ovos de páscoa... Tua mãe, minha mãe... Nossos primos, tios, irmãos... Muito amor, né?" 


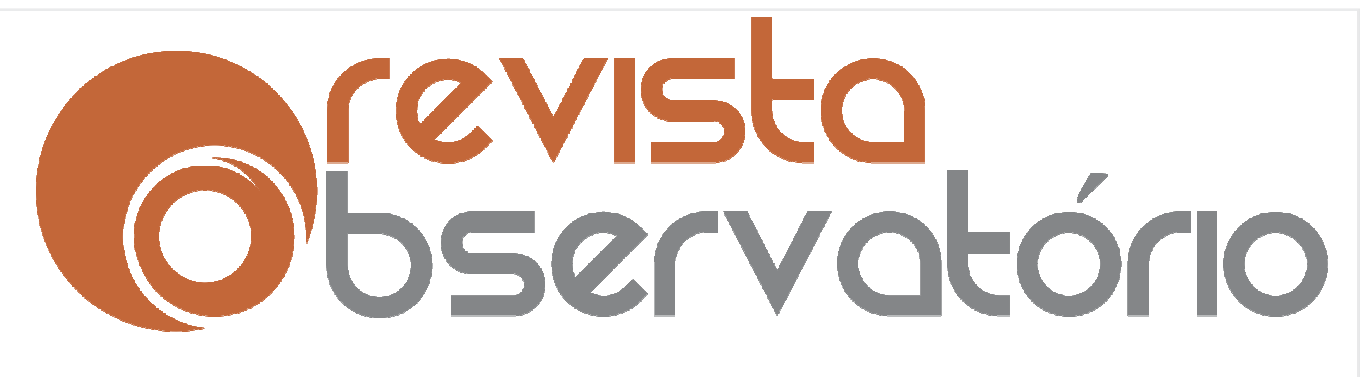

DOI: http://dx.doi.org/10.20873/uft.2447-4266.2015v1n3p181

Observações: O início do filme é a representação de uma brincadeira de Páscoa, em que uma pessoa mais velha esconde os ovos de chocolate para que as crianças os "cacem". Nesta sequência, é dona Nadyr (mãe de Márcio) quem esconde os ovos. Márcio Assis e a atual esposa, Adélia Maria César Gelmi de Assis, não conseguiram identificar de quem era o batizado no evento exibido na sequência seguinte. Segundo Márcio, o jogo de futebol foi filmado aleatoriamente - quem jogava eram alguns moradores do bairro Floresta, Márcio Assis apenas assistia. Os comentários ressaltam a lembrança das brincadeiras de criança feitas pelos membros da família; demonstram que estes sentem falta dos momentos felizes vividos naquela época; depois de assistir a esse filme, que ficou muito tempo guardado, os familiares foram tomados por um desejo de ter e ver mais daqueles instantes e sentir de novo as emoções por imagens como aquelas.

2) Maio e julho 1974

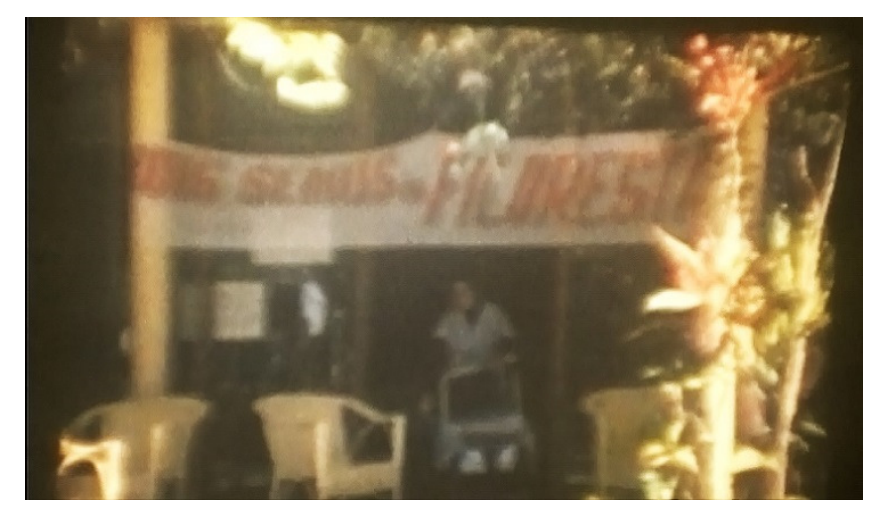

Figura 02: Faixa "Nois semos da Filoresta", utilizado para recepcionar Regina de Assis no aeroporto do Galeão. Ano: 1974.

\section{Comentários no grupo "Primaiada"}

- Regina de Assis: "Que tempo bom! Chegando dos States, no antigo Galeão, com a Família inteira segurando a faixa: "Nóis semos di Filoresta!" Papai, Mamãe, Tia Noemí, Júlio Cesar, Ana Anita, Fernando, Ana Luísa, Caio, Dalva, Márcio, Rita, Jolly, 


\section{Observotório}

DOI: http://dx.doi.org/10.20873/uft.2447-4266.2015v1n3p181

Julinho, ô, alegria grande! Depois a Paz, o calor e a beleza do Rancho Alegre, com Alzira, o macaco, o tucano. Dalva com Mariana pequenininha, vivam as boas memórias que o Super8 e Márcio estão trazendo com Ana Clara!

- Carlinha de Assis: "Ai, meu Deus! Que lindo! Vovô Júlio, pai, tio Fernando, tio Caio, tia Noemi... Saudadessssssssssssssssssssssssssssssss"

Observações: Luís Otávio, o homem que "brinca" com as cobras, alugava um apartamento do irmão de Márcio. Ele não se lembra qual a profissão de Luís, apenas que esse homem tinha um grande interesse por cobras e que entregava-as ao Butantã depois de criá-las. A chegada de Regina de Assis no aeroporto do Galeão assemelha-se à história vivida por Márcio Assis em 1970: naquele ano, ele viajou pela Europa e pelos Estados Unidos. Quando chegou, foi recepcionado pela família e pelos amigos, assim como Regina de Assis. De acordo com Márcio Assis, a faixa "nois semos da filoresta" foi a forma que a família usou para caracterizar a linguagem simples, de pessoas "da roça", que estavam no Galeão para receber Regina de Assis. Márcio Assis também afirma que o Rancho Alegre sempre teve muitos animais: cachorro, gato, papagaio, periquito, arara, tucano e até jacu, macaco e esquilo. Nos comentários do grupo "Primaiada", é ressaltada a presença querida dos animais de estimação naquele ambiente rural (é notável que o macaquinho era um dos mais queridos, pois seu nome foi lembrado por Márcio e por Ana Carolina Assis, ele chamava-se Chico); a tranquilidade campestre do Rancho Alegre também é lembrada; os parentes que se foram são motivo de um forte sentimento de saudosismo. 


\section{Obsevisto}

ISSN n² 2447-4266

Vol. 1, n³, dezembro. 2015

DOI: http://dx.doi.org/10.20873/uft.2447-4266.2015v1n3p181

3) Casório de Rita e Márcio (19/07/1975)

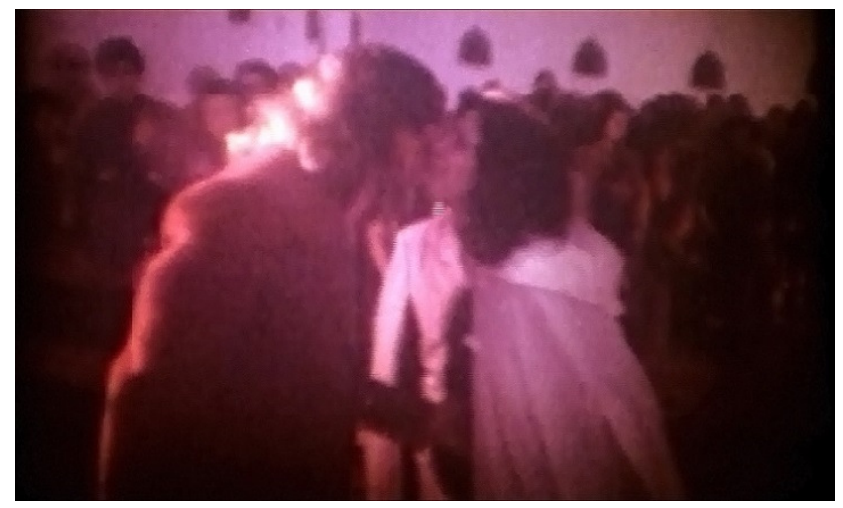

Figura 04: Os noivos Márcio Assis e Rita Marques se encontram e se cumprimentam no altar. Ano: 1975.

\section{Comentários no grupo "Primaiada"}

- Mônica de Assis Delmonte: "Que legal!! Lembro do seu casamento, Tio Márcio Assis, em flashes, lembro de você ir se arrumar em nossa casa e sentir dor de dente... Rsrsrs... Lembro da minha roupa de daminha de honra que eu amava... Dos meus primos e irmãs, tios, pai, mãe, avós... Tantas recordações felizes!!! Obrigada, @anaclaracampos!!! Muito sucesso para você!!! Bjs."

- Regina de Assis: "Até que enfim assisti ao casamento, pois neste tempo estava fora do Brasil, em NYC. Que coisa boa ver vocês cabeludos, Papai, Mamãe, Dr. Cássio, Dona Gioconda, Tia Noemí, Jolly e Munika de daminhas. Valeu!"

- Bianca Marques: "Gente, sem palavras... Muita gratidão por isso ter sido registrado".

Observações: As cenas são do casamento de Assis com sua primeira esposa. Márcio Assis tinha 24 anos e Rita Marques, 18. Ele lamenta o fato de o vídeo não ter som, pois as músicas foram compostas e tocadas por amigos musicistas. A noiva veste-se com um vestido diferente do comum: ao invés do véu, ela carrega um capuz 


\section{Observotório}

DOI: http://dx.doi.org/10.20873/uft.2447-4266.2015v1n3p181

na cabeça. A vestimenta de Márcio Assis também merece atenção: o terno era de veludo vermelho e a gravata borboleta, também vermelha. As imagens do casamento desencadeiam outras lembranças, além das que são exibidas. Mônica, que era criança, lembra-se que o tio sentiu dor de dente enquanto se arrumava para o casamento, fato que nem ao menos deixa um sinal no filme. Ela também se lembra do vestido que usou como dama de honra, que não mostra, apenas pelas imagens do filme, como ela gostava daquela roupa. Para Regina de Assis, a postagem do filme foi uma oportunidade de assistir a um evento ao qual não pode estar presente, já que se encontrava bem longe, fora do país. Já a filha de Márcio Assis e Rita Marques, Bianca Assis, sente gratidão por aquelas cenas terem sido registradas e veiculadas, dando a oportunidade a ela de também ter acesso a um evento que aconteceu dois anos antes de seu nascimento.

\section{Conclusões}

Por meio dos comentários, podemos observar as diversas emoções acarretadas por aquelas imagens: a alegria de rever pessoas amadas; um saudosismo pelos momentos mostrados, sempre tão felizes; a gratidão por aqueles momentos terem sido registrados e se tornado acessíveis a todos; a expectativa de assistir a mais filmes como aqueles; os sentimentos aconchegantes que as imagens trouxeram de paz, calor e beleza; flashes de outras lembranças, não mostradas nos filmes (a dor de dente do tio, enquanto ele se arrumava para o casamento); alegria de poder assistir a um evento no qual não esteve presente (Regina de Assis não pode ir ao casamento do irmão, pois, na época, estava fazendo pós-graduação nos Estados Unidos).

Em um breve depoimento, Mariana Assis (sobrinha de Márcio) se mostrou muito feliz em ter acesso às imagens, e com um sentimento nostálgico em relação aos parentes que já se foram e à infância. Além disso, viu as cenas como se fossem 


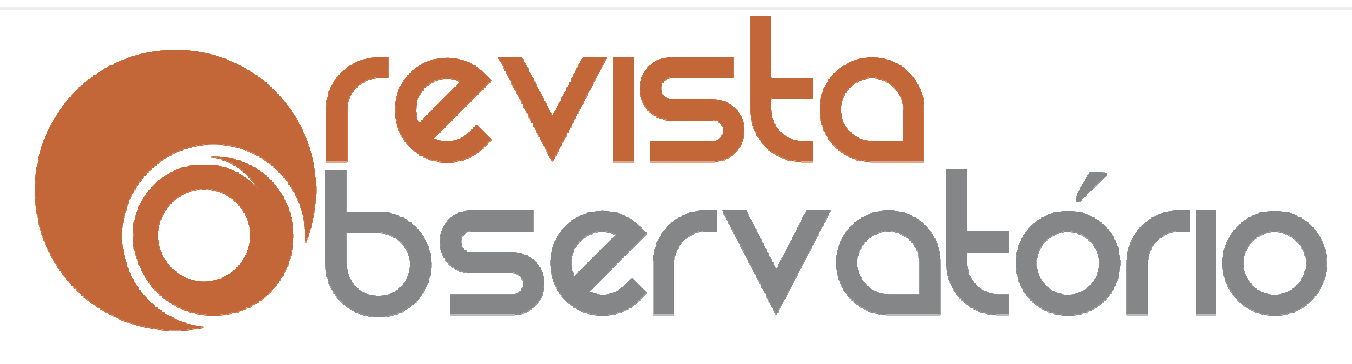

DOI: http://dx.doi.org/10.20873/uft.2447-4266.2015v1n3p181

parte de um sonho bom: "Fiquei muito emocionada, chorei ao ver meu pai, vô, tios falecidos... e nossa linda infância dourada no jardim do sítio (...) Era uma vida muito boa... Parecia um sonho mesmo, como se eu estivesse vendo cenas de um sonho..." (ASSIS, Mariana. 2014).

A filha de Márcio, Bianca Marques Vieira de Assis, ao falar sobre a experiência de assistir aos filmes, comentou que ficou "extremamente tocada com a delicadeza das imagens" e que se sentiu emocionada por esses momentos terem sido registrados e poderem ser resgatados. "É muito bom poder assistir cenas familiares tão lindas e saber que isso de alguma maneira foi registrado e agora pude ter contato com essas imagens" (ASSIS, B., 2014).

Os filmes 1 e 2 têm uma característica em comum: a atenção dispensada às crianças da família. De acordo com os estudos do pesquisador Armando Silva (2008), sobre álbuns de família, ele conclui que, estatisticamente, "os filhos dominam o panorama, em especial como mostram os álbuns dos anos 1970 em diante" (SILVA, 2008, p.61). De acordo com esse fato apontado por Silva, podemos observar que grande parte das cenas dos filmes citados tem como protagonistas as crianças e suas brincadeiras, ao invés das cenas em que aparecem os mais velhos da família (dona Nadyr e senhor Júlio, pais de Márcio).

Percebemos como os filmes domésticos, a bitola Super 8 e os estudos sobre memória estão intimamente interligados, de modo que, na maioria das vezes, os registros relacionados a esses três pontos possuem uma atmosfera onírica de felicidade e geram o desejo de perpetuar as lembranças para as gerações posteriores. Falar de Super 8 nos dias atuais é falar da memória dos anos 1970 no Brasil e no mundo. Falar de filmes domésticos é falar de Super 8, uma câmera simples na época e facilitadora do gênero caseiro.

Concluímos que a memória afetiva permite o estreitamento dos laços de identidade que unem um grupo, devido às lembranças vividas com os outros integrantes desse grupo. Notamos que os momentos felizes e de saudosismo são os 


\section{Observatório}

DOI: http://dx.doi.org/10.20873/uft.2447-4266.2015v1n3p181

que predominam na narrativa da família; especificamente neste trabalho, cujos filmes foram feitos na década de 1970 - a época em que os mais novos viveram uma infância tranquila e amorosa, e momento de luta por ideais em meio ao regime ditatorial, para a geração que os antecede.

A década de 1970 foi marcada pela dificuldade em se obter informação, devido à censura da ditadura militar. Diferente de hoje, momento em que a tecnologia e a informação circulam em ritmo muito mais acelerado. Também por causa das facilidades que a tecnologia proporciona, é espantoso o número de produção de arquivos domésticos e pessoais. Isso se deve a uma luta contra a fugacidade, contra o medo da "morte", ao receio de esquecer os eventos felizes do dia a dia, ao receio de ser esquecido. Com isso, poderíamos defender o porquê do grande número de registros que fazemos todo o tempo: desejamos a preservação de nós mesmos, de nossa identidade e de nossos grupos sociais para que as próximas gerações tenham acesso a todas as informações que não tivemos.

\section{Referências}

ÁLVAREZ, Efrén Cuevas. De vuelta a casa: Variaciones del documental realizado con cine doméstico. In: La casa abierta: el cine doméstico y sus reciclajes contemporáneos. Ayuntamiento de Madrid, 2010. p. 121-166.

ASSIS, Bianca Vieira Marques. Filmes domésticos de Júlio e Márcio Assis. 25 jun. 2014. Depoimento concedido a Ana Clara Campos dos Santos por meios eletrônicos.

ASSIS, Ana Carolina Furtado de. Filmes domésticos de Júlio e Márcio Assis. Juiz de Fora. 16 mai. 2014. Depoimento concedido a Ana Clara Campos dos Santos em áudio.

ASSIS, Márcio de Alcântara. Comentários dos filmes do acervo de Super 8 de Márcio Assis. Juiz de Fora. 11 mai. 2014. Depoimento dado a Ana Clara Campos dos Santos em áudio.

ASSIS, Mariana Furtado. Filmes domésticos de Júlio e Márcio Assis. 26 jun. 2014. Depoimento concedido a Ana Clara Campos dos Santos por meios eletrônicos. 


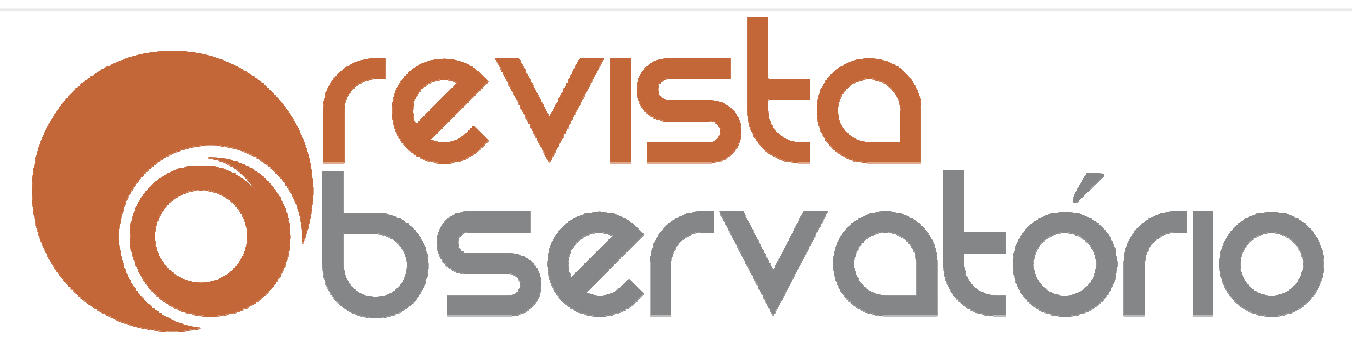

DOI: http://dx.doi.org/10.20873/uft.2447-4266.2015v1n3p181

CARUSO, Carlos Alberto Antonio. Conceitos fundamentais para o estudo do filme doméstico. In: O filme de família: O Fascínio da Preservação da Imagem, Histórias e Memórias. 2012. Dissertação (Mestrado em Comunicação) - Universidade Anhembi Morumbi, São Paulo, 2012. cap. 01, p. 13-32. Disponível em: $<$ http://portal.anhembi.br/wpcontent/uploads/Dissertacao_Carlos_Alberto_Antonio_Caruso1.pdf>. Acesso em: 11 mar. 2015.

DARGY, P. A prática do super 8 / P. Dargy, N. Bau; adaptação e prefácio da ed. Brasileira de Abrão Berman; (tradução de Luiz Roberto S. Malta). - 4. ed. - São Paulo: Summus, 1979.

FOSTER, Lila Silva. Conceitos fundamentais para o estudo do filme doméstico. In: Filmes domésticos: uma abordagem a partir do acervo da Cinemateca Brasileira. 2010. Dissertação (Mestrado em Imagem e Som) - Universidade Federal de São Carlos, São Carlos, 2010. cap. 01, p. 17-53. Disponível em: <http://www.bdtd.ufscar.br/htdocs/tedeSimplificado/tde_busca/arquivo.php?codArqu ivo=2965> . Acesso em: 11 mar. 2015.

HOME Movie Day Rio. 2013. Apresenta informações sobre inscrições e programação do evento Home Movie Day Rio, ano de 2013. Disponível em: <http://homemoviedayrio.wordpress.com/>. Acesso em: 11 mar. 2015. Site.

HUYSSEN, Andreas. Passados presentes: mídia, política, amnésia. In: Seduzidos pela memória: arquitetura, monumentos, mídia. 2. ed. Rio de Janeiro: Aeroplano, 2004. cap. 01, p. 09-40.

LEAL, Marília Muniz. Filmes de família: lembrança e documento. 2013. 62 f. Monografia (Bacharel em Comunicação Social, habilitação cinema). Universidade Federal Fluminense, Niterói, 2013. Disponível em: <http://www.rascunho.uff.br/ojs/index.php/rascunho/article/view/49/31 >. Acesso em: 11 mar. 2015.

LINS, Consuelo; BLANK, Thais. Filmes de família, cinema amador e a memória do mundo. Significação. Vol. 39, $\mathrm{n}^{\circ} \quad 37,2012$. p. 52-54. Disponível em: <http://www.revistas.usp.br/significacao/article/view/71254>. Acesso em: 11 mar. 2015.

NORA, Pierre. Entre memória e história: a problemática dos lugares. In: Projeto História. São Paulo, dez. 1993. p. 07-28.

ODIN, Roger. El cine doméstico en la instituición familiar. In: La casa abierta: el cine 


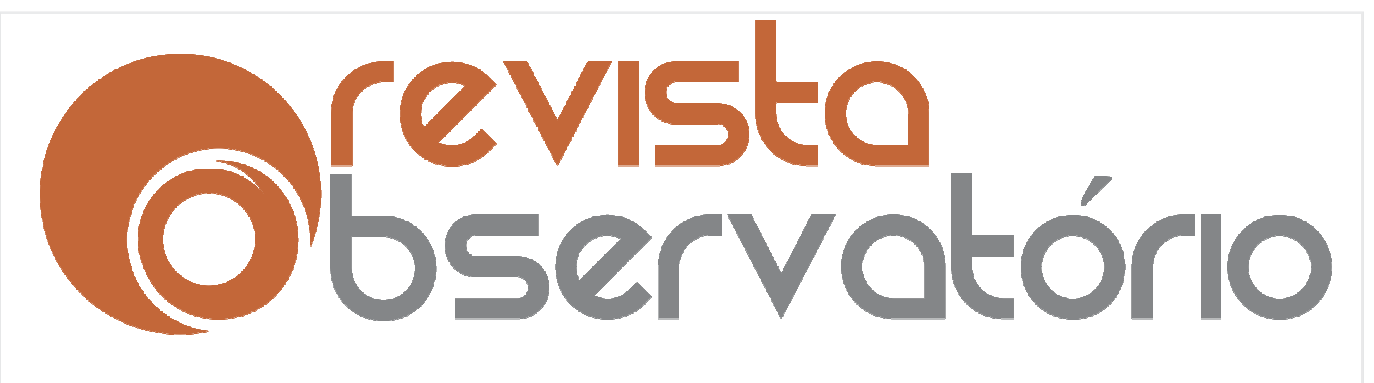

ISSN n² 2447-4266

Vol. 1, n 3, dezembro. 2015

DOI: $\underline{\text { http://dx.doi.org/10.20873/uft.2447-4266.2015v1n3p181 }}$

doméstico y sus reciclajes contemporáneos. Ayuntamiento de Madrid, 2010. p. 39-60.

SILVA, Armando. O arquivo do álbum de fotografias. In: Álbum de família: a imagem de nós mesmos. São Paulo: Senac, 2008. cap. 02, p. 41-75.

Acesse esse e outros artigos da Revista Observatório em:

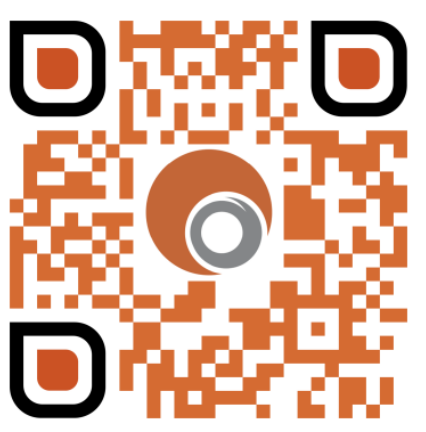

